\title{
TRANSLATIONAL MEDICINE AT THE INTERSECTION OF EVIDENCE-BASED MEDICINE AND NARRATIVE MEDICINE
}

\author{
Alberto C. S. Costa ${ }^{1}$
}

The content of this editorial is based on the keynote speech I delivered at the Sixth International Congress on Health Issues in Childhood and Adolescence (http://congressocisca.com.br/) held at the School of Public Health, University of São Paulo, Brazil, on May 2015. On that occasion, I told two parallel stories to the audience. First, I talked about the many, sometimes-misguided decisions that made me into the professional researcher in the field of Translational Medicine that I am today. Second, I described some of the historical landmarks that led to the development of the field of Evidence Based Medicine, and the consequences of this development for the current teaching and practice of medicine.

I received my medical degree from the State University of Rio de Janeiro (Universidade Estadual de Rio de Janeiro - UERJ) in 1986. When I enrolled at the School of Medicine at UERJ, I was naïve enough not to know that that specific Medical School represented one of the last bastions of "traditional medicine" in Brazil, which is now known as Experience-based Medicine. For example, teaching at the State University of Rio de Janeiro was still based on traditional medical disciplines (i.e., anatomy, physiology, pharmacology, pathology, etc.), compared with the more contemporary medical curriculum at the Federal University of Rio de Janeiro (Universidade Federal do Rio de Janeiro - UFRJ), which was based on systems. Although considered outdated now, the traditional approach used by my old medical school produced an infernal repetition of the same issues from semester to semester, but it also guaranteed that the information ultimately made an indelible mark in the brain of the poor student. In addition, the curriculum of UERJ was completely rigid, and did not allow the student to "stray" into non-medical disciplines. In contrast, the UFRJ allowed the student who had interests other than medicine to take classes in subjects other than those offered by the medical curriculum. Such rigidity at my medical school was also a torture for me, given that I was a student who had come from a federal technical school (CEFET-RJ) and, since day one, had the dream of becoming a physician-scientist.

UERJ was also Brazil's most traditional of Brazil's traditional medical schools in other ways. For example, most of the third year of medical school at UERJ was dedicated to medical propaedeutics (or propedeutics), and we spent most of the day in medical wards of various specialties, learning to collect medical histories and doing physical exams. Initially, this was also a nightmare for me. Nevertheless, exactly because I had no other options, little by little, I became more and more comfortable at interacting with patients, and skillful in recognizing signs and symptoms of various diseases and disorders that can affect human beings, which are skills that serve me well until this day.
During my clinical rotations, I had excellent mentors, such as Drs. Jose Augusto Fernandes Quadra, Fernando Bevilacqua, Jayme Landmann and Pedro Sampaio. All these individuals had in common an immense amount of knowledge, tremendous passion for the art of medicine, and egos commensurate with these attributes. They rarely allowed the student or resident to question their clinical assessments, regardless of whether such opinions were based on scientific evidence or not (except, perhaps, Dr. Quadra; but that man was never wrong anyway...). "Clinical knowledge is king!" This is what they used to say.

In 1987, I was ecstatic because I thought I had finally abandoned medicine after six torturous years of medical school. I had been accepted into the graduate program at the Institute of Biophysics Carlos Chagas Filho at UFRJ (IBCCF-UFRJ), where I would devote myself completely to the practice of basic science. Despite having taken classes with luminary figures such as Professor Aristides Leão and the late Professor Carlos Chagas Filho himself, I noticed immediately a huge difference in the approach to teaching at the IBCCFUFRJ compared with my experience in medical school. In this new environment, the student had been always encouraged to question everything that was being said. Information was always presented as potentially falsifiable; which is typical of the scientific attitude.

After a year and a half taking classes and learning laboratory techniques as a graduate student at IBCCFUFRJ, I spent two and a half years on a research fellowship at the Department of Pharmacology in the University of Maryland. This was followed by my return to the IBCCF in 1991 to defend my doctoral thesis in Biological Sciences (Biophysics). From there, I went to Baylor College of Medicine, in Texas, where I did four and a half years of postdoctoral training in Neuroscience.

In 1992, the article "Evidence-based medicine. A new approach to teaching the practice of medicine" was published in the Journal of the American Medical Association, JAMA ${ }^{1}$. After some pushback from leading practitioners of Experience-based Medicine, this emerging field underwent rapid ascension among the medical establishment. Below are some comments extracted from the editorial published in the British Journal of Medicine in 1996 by Sackett et al. ${ }^{2}$, which addresses some of the initial criticism directed against the original article:

- "Evidence based medicine is the conscientious, explicit, and judicious use of current best evidence in making decisions about the care of individual patients. The practice of evidence based medicine means integrating individual clinical expertise with the best available external clinical evidence from systematic research. By individual clinical expertise we mean the

1 Departments of Pediatrics and Psychiatry, Case Western Reserve School of Medicine, Cleveland - USA.

Corresponding author: Alberto C. S. Costa. E-mail: Alberto.Costa@case.edu

Suggested citation: Costa ACS. Translational medicine at the intersection of evidence-based medicine and narrative medicine. Journal of Human Growth and Development. 2015; 25(2): 253-256. Doi: http://dx.doi.org/10.7322/jhgd.105997

Manuscript submitted: august 16 2015. Accepted for publication: august 232015. 
proficiency and judgment that individual clinicians acquire through clinical experience and clinical practice. Increased expertise is reflected in many ways, but especially in more effective and efficient diagnosis and in the more thoughtful identification and compassionate use of individual patients' predicaments, rights, and preferences in making clinical decisions about their care. By best available external clinical evidence we mean clinically relevant research, often from the basic sciences of medicine, but especially from patient centred clinical research $[\ldots] . "$

- "External clinical evidence both invalidates previously accepted diagnostic tests and treatments and replaces them with new ones that are more powerful, more accurate, more efficacious, and safer." [Falsifiability!]

- "Good doctors use both individual clinical expertise and the best available external evidence, and neither alone is enough."

In 1996, I landed my first independent appointment as a Research Scientist at The Jackson Laboratory, in Maine, an institution that was at the center of the genetic revolution and that has played an integral part to translational medicine.

In the year 2000, I moved to Colorado, where I worked as an Institute Scientist, and then Research Associate Professor at the Eleanor Roosevelt Institute, which was the only American research center that participated in the sequencing of the human Chromosome 21. In that institution, I began to carry out pharmacological studies on mouse models of Down syndrome and started doing quantitative neurophysiological assessments in persons with Down syndrome.

In 2006, I became Associate Professor in the Department of Medicine of the University of Colorado. There, I began to design and run clinical trials in persons with Down syndrome, and to attend regularly my department's clinical grand rounds. Then, in 2011, I became co-director of the Clinical Pharmacology Course, which was an elective course taken by fourth year medical students. My unexpected reunion with the field of medicine, and my almost accidental involvement in medical education, led me to countless hours of reflection on the medical curriculum in the United States in the 2010's, on how it compared to the education I had received in Brazil in the 1980s, and on how the practice of medicine had changed as a result of this spatiotemporal displacement.

For beginners, medicine in the United States is a professional graduate-level school, which generally follows a four-year college education that contains a series of pre-medical prerequisite credits. After graduation in medical school, the students receive the title of doctor of medicine (medical doctor, or MD). This is followed by a one-year postdoctoral internship, then, by residency training in a major medical specialty, and, finally, by optional fellowship training; if such medical doctor decides that he/she wants to pursue subspecialty training.

In contrast, in Brazil (like in most countries in the world) students go into medical school straight from high school, which can partially be justified by differences in high school education between the two countries. Back in the early 1980's most Brazilian medical students used to receive five years of classroom medical school education, which helped narrow a little bit the gap in years of formal education between the countries. This used to be followed by one year of predoctoral internship, after which the student would receive the professional physician title (the Brazilian equivalent to an MD). Similar to what happens in the United States, newly minted physicians would then pursue residency and, potentially, fellowship training. It is actually sad to realize, however, that the so- important fifth year of formal medical education has now been deleted from the medical school curriculum, and replaced with a second year of pre-doctoral internship. The consequences of removing this fifth year of education are difficult to quantify, but, given that these students already got into medical school without any previous college education, it is hard to believe that this has had a positive effect. Perhaps the best data supporting this assumption comes from the recent report by the Regional Medical Board of São Paulo (Conselho Regional de Medicina de São Paulo; http:// www. cremesp.org.br/?siteAcao $=$ NoticiasC\&id $=3501$ ), which found that $55 \%$ of the newly-graduated physicians in Brazil's most powerful state failed to obtain a passing grade (i.e., $60 \%$ correct answers on a test of general medical knowledge) on the mandatory state board exam.

In addition to the direct educational advantages of medical school being a professional, graduate-level course in the United States, because they are in average four years older, in general, American medical students are typically emotionally more mature then their Brazilian counterparts. This is mostly noticeable in the early years of training.

As a faculty member at the University of Colorado, I became familiar with an interesting ritual that exemplifies the maturity of the first year American medical students. At the end of the first year of medical school, the students had the opportunity to participate in a social ceremony where they would meet with the family members of donor cadavers they dissected as part of their Human Anatomy training. Seeing how those first-year students approached this, could only bring shame to me, as I remembered the immature 18-year old me finishing my first year of medical school and my complete lack of regard for the personal history of cadavers that I had the privilege of dissecting...

In 2013, I moved to Case Western Reserve University, Ohio. Today, I am Professor of Pediatrics and Psychiatry, and Director of the Intellectual Disability Program at The Research Institute for Children's Health (RICH). At this stage of my career, I have become more and more involved in the field of Translational Medicine. My focus continues to be the search for potential therapies to improve cognition and potentially slow down the progression of neurodegeneration in persons with Down syndrome. In this capacity, I get to design and perform both preclinical studies in animal models and clinical trials in human participants.

In dealing with the intricacies associated with the effective and ethical translation of laboratory data into potentially clinically relevant information, frequently, I catch myself reflecting on or even debating certain issues that had been long dormant in my brain, such as history of medicine, medical education in the $21^{\text {st }}$ century, and the current state and the future of clinical practice. This is because, whether I like to admit it or not, Translational Medicine is a form of medicine. And, over the past decade, little by little, I have become a practitioner of this non-traditional type of medicine.

Translational Medicine is a discipline within the realms of biomedical research and public health aimed at improving the health of individuals and the community ${ }^{3}$. The Institute of Medicine's Clinical Research Roundtable helped define this field through the description of two "translational blocks" in the clinical research enterprise, which were later labeled as T1 and T2. The first roadblock (T1) was described as "the transfer of new understandings of disease mechanisms gained in the laboratory into the development of new methods for diagnosis, therapy, and prevention and their first testing in humans." The second roadblock (T2) was "the translation of results from clinical studies into everyday clinical practice and health decision making." By translating scientific 
findings into diagnostic tools, therapies, procedures, policies, and education, translational medicine has rapidly grown in its ability to accelerate discovery.

In the field of translational medicine, I have encountered something that I find both meaningful and rewarding, and it fits almost perfectly my professional training. Translational Medicine provides the clinically relevant research necessary to inform the practice of Evidence Based Medicine. Unfortunately, however, many fail to recognize that the methods and goals of Translational Medicine do not always coincide with those of Evidence Based Medicine.

When a researcher designs a clinical study, frequently, the goal is to test whether a given therapy shifts positively the mean value of the primary efficacy outcome measure in a group of treated participants compared with a placebo or standard-treatment group. Ideally, the study is designed in such way that neither those administering the therapy nor those receiving the therapy know what treatment is being administered (i.e., double blind study). In addition, it is important that the sample size is large enough to give the study enough statistical power to allow reasonable generalizations of the study findings to the entire population of individuals affected by the disorder or disease for which one hopes to find a treatment. If the study is successful, the investigators will report the finding that the treatment positively and significantly affected the mean value of the primary efficacy outcome measure, with minimal adverse events. Therefore, it can be argued that clinical investigators are trying to "treat the mean" of their study subjects. In contrast, a physician in clinical practice is interested in treating "the individual patient" in his/her practice. There are many other important differences, which are determined by the clinical study design. For example, to avoid potential confounders, clinical investigators will establish a set of a priori inclusion and exclusion criteria for participation in a clinical trial, which somewhat "homogenizes the sample". In everyday practice, however, a physician typically has little choice but to try to offer treatment to all patients, whether or not they fit neatly into the confines of the design of the study that led to the approval of such treatment in the first place. Although many other differences and limitations could be listed here, doing so would go beyond the scope of the present text. Suffice to say that failure to recognize the limitations of even the best-designed clinical studies in terms of their usefulness to day-to-day clinical practice, which necessarily should deal with individual variations, often lead to distortions and excesses in the application of the principles of Evidence Based Medicine.

Discontentment with the current state of affairs, which has been voiced by many practitioners in recent years, was described eloquently in a recent op-ed published by the cardiologist Dr. Sandeep Jauhar in the New York Times in December 10, 2014 (http:// www.nytimes.com/2014/12/11/opinion/donthomogenize-health-care.html? $r=0)$, with the headline: "Don't Homogenize Health Care." He starts his text by saying that in "American medicine today, "variation" has become a dirty word. Variation in the treatment of a medical condition is associated with wastefulness, lack of evidence and even capricious care." He then goes on to describe how insurers and medical specialty societies have joined forces "to produce a dizzying array of treatment guidelines for everything from asthma to diabetes, from urinary incontinence to gout." He admits that "some types of variation are unwarranted, even deadly", and even cites data indicating that " 57,000 Americans die each year because the care they get is not based on the best available evidence." Then, he reasons, "the effort to homogenize health care presumes that we always know which treatments are best and should be applied uniformly." However, as he contends, "evidence for most treatments in medicine remains weak. In the absence of good evidence recommending one treatment over another, trying to stamp out variation in care is irrational."

One of the unintended consequences of the almost blind reliance on published evidence over the kind of professional common sense acquired through many years of clinical practice that used to be the main guide of physicians in the past is an overall sense of loss of autonomy in the medical profession. Formerly, clinical knowledge used to be king, but, presently, published evidence, from clinical trial results and metaanalyses, is the new king! Are we ever going to abolish monarchy in medicine?

Many physicians see the growing number of treatment guidelines, along with the dwindling compensation for time spent with the patient, as limiting factors to their professional freedom. In the United States, physicians are frustrated with the profession in numbers never seen historically. A 2010 survey by The Physicians Foundation ${ }^{4}$, found that $40 \%$ of practicing physicians considered quitting patient care in the next 1-3 years, either by retiring or seeking a non-clinical job in healthcare, or seeking a job or business outside of healthcare. However, it should be mentioned that, as pointed by the authors of the survey, "historically, physician dissatisfaction has not been a major contributing factor to physician attrition." Nevertheless, there also has been a well-documented increase in the rate of physician burnout, which is characterized primarily by work-related emotional exhaustion. A recent analysis of correlates of physician burnout across regions and specialties, identified autonomy at the workplace as the strongest correlate to work engagement ${ }^{5}$. Accordingly, practitioners in outpatient specialties in managed care systems may experience negative health states due to the highly regulated environment, which limits their autonomy, decision making and ability to develop lasting professional relationships with patients ${ }^{6}$. Physician burnout has been associated with affective disorders, alcoholism, and substance abuse, which are all common psychiatric diagnoses among physicians who commit suicide. It has been estimated that, on average, 400 physicians in the United States commit suicide each year (the equivalent of an entire medical school per year; http:/ /emedicine.medscape.com/article/806779).

I am fortunate to be a faculty member in two clinical departments at Case Western Reserve University (CWRU) School of Medicine, an institution that, for more than 160 years, has earned an international reputation for excellence in medical education and research. In addition, CWRU School of Medicine has been at the forefront of the development of medical curricula for almost 70 years. Three CWRU School of Medicine educators (Drs. Joseph T. Wearn, T. Hale Ham, and John L. Caughey, Jr.) were recipients of the Association of American Medical Colleges' Abraham Flexner Award for Distinguished Service to Medical Education for developing and implementing the 1952 curriculum; and Dr. Frederick C. Robbins won the Flexner award in recognition of his educational leadership. The 1962 paper published by the New England Journal of Medicine describing the CWRU School of Medicine's then new curriculum ${ }^{7}$ gave rise to what is now known as the major curriculum "revolution" of 1952. It originated the integrated organ systems approach, which enables meaningful interdisciplinary learning of themes rather than scattered disciplinary factual medical knowledge ${ }^{8}$. In the subsequent decades, this approach was adopted by most major universities across the world, including the Federal University of Rio de Janeiro (UFRJ). However, as aforementioned, 
my alma mater, the State University of Rio de Janeiro (UERJ) was one of the slow adopters of the major curriculum "revolution" of 1952. The UERJ was also slow at fully supporting basic biomedical research. Consequently, and unfortunately, this medical school saw a steady decline of national prestige from the final decade of the $20^{\text {th }}$ century into the first decade of the $21^{\text {st }}$ century.

CWRU School of Medicine is now one of a dozen of leading American medical school involved on a national effort to design and implement a new "medical curriculum revolution for the $21^{\text {st }}$ century". This new curriculum is supposed to make heavy use of technological tools, as well as producing more collaborative physicians, who can be at ease discussing clinical cases and therapeutic strategies among peers of their subspecialty, as well as with members of different medical specialty, basic scientists, and members of completely different disciplines. For example, through an exciting partnership with Microsoft Corporation, CWRU School of Medicine is pioneering the teaching of human anatomy through the use of HoloLens (http://case.edu/hololens/). Therefore, when it is inaugurated in 2019, our new medical education building will be at the core of one of the very first cadaver-free medical schools in the United States.

As I wind down this narrative, it may have become apparent to the reader of this editorial that I am ambivalent about many new developments in the teaching and practices of medicine. My perspective on the subject is obviously different from the average physician, as I do not have to endure daily clinical practice. Also, I am now old enough that I may have started to romanticize a medical training that was truly traumatic at the time. However, like many others of my generation, I see a progressive loss of the human dimension in the modern practice of medicine as a problem to be addressed. Buzzwords like "personalized medicine" (which, recently, is starting to be replaced by "precision medicine") can be quite empty in meaning if the human person with all his/her idiosyncrasies, dimensions, and "inconvenient variations" is not brought back to the fore of our profession.

Although I loathed every single minute I spent dissecting cadavers in anatomy class, I also feel it was a necessary introduction to the frequent encounters between the physician and the finality of human life. Such introduction served me very well when, years later I "lost" my first patient while moonlighting in the Emergency Room as a senior medical student. It was only after 25 years, however, in a distant medical schoo in my new, adopted home country that I was finally

\section{REFERENCES}

1. Evidence-Based Medicine Working Group.Evidencebased medicine.A newapproach toteaching the practice of medicine. JAMA. 1992;268(17): 24205.

2. Sackett $D L$, Rosenberg WM, Gray JA, Haynes RB, Richardson WS. Eviidence based medicine: what itis and what it isn't. BMJ. 1996; 312 (7023): 712.

3. Woolf SH. The meaning of translational researchand why it matters. JAMA. 2008; 299(2): 211-13. DOI: http://dx.doi.org/10.1001/jama. 2007.26

4. The Physicians Foundation. Health Reform and theDecline of Physician Private Practice. White Paperand survey conducted on behalf of The PhysiciansFoundation by Merritt Hawkins. [cited2010 ouct 20] Available from: http:// www.physiciansfoundation.org.

5. Lee RT, Seo B, Hladkyj S, Lovell BL, SchwartzmannL. Correlates of physician burnout across regionsand specialties: a meta-analysis. able to reconcile my feelings, and understand how that experience could be improved greatly by adding back the human dimension to the anonymous body donor. As a practicing scientist, I am obviously very adept and comfortable with the use of technology. Nevertheless, physicians are supposed to serve individual patients, and technology should be used as a means to enhance, not diminish the human contact between the clinician and the patient. Medical education in the $21^{\text {st }}$ century definitely needs its own revolution and it will benefit greatly from the many lessons acquired from the practice of evidence-based medicine. But such revolution will not be effective if students are not strongly mentored on how to empathize with other human beings, to listen to their stories, and to respect their basic humanity. I am optimistic that, as they have done many times before, CWRU School of Medicine and others at the vanguard of the new curriculum revolution will find clever ways of enhancing the human dimension of medical training. Because, long-term satisfaction with the practice of medicine will depend not only on the enhancement of communication, teamwork, and of a sense of shared purpose, but also on enhanced respect for the individual, which should be interpreted both as deep respect for the humanity of the individual patient and as respect for professional autonomy of the physician.

An interesting movement that is starting to emerge is the birth of the so-called Narrative Medicine, which recognizes the value of people's narratives in clinical practice, research and education. At its core, Narrative Medicine aims not only at validating the experience of the patient, but also at encouraging creativity and self-reflection in the physician. Columbia University has pioneered this field by creating, in 2009, a master's program in Narrative Medicine (http:// www.narrativemedicine.org). Personalized Medicine many times sounds like a hollow promise, because of the growing disparities in access to state of the art medical care in the United States and throughout the world. Similarly, Narrative Medicine also may sound like a difficult-to-implement project, given the evershorter time that the typical physician is expected to spend with his/her patient. Still, movements such as Narrative Medicine give me hope that the practice of medicine will continue to evolve, but it will not forget its roots.

In the end of the day: "Medicine is a science of uncertainty and an art of probability." (William Osler ${ }^{9}$ )

And: "The Universe is made of stories, not of atoms." (Muriel Rukeyser ${ }^{10}$ )

Hum Resour Health. 2013;11:48. DOI: http:// dx.doi.org/10.1186/1478-4491-11-48.

6. Shanafelt TD, West CP, Sloan JA, Novotny PJ,Poland GA, Menaker R, et al. Career fit and burnout among academic faculty. Arch Intern Med. 2009; 169 (10): 990-5. Doi: http://dx.doi.org/10.1001/ archinternmed. 2009.70.

7. Ham TH. Medical education at WesternReserve University: a progress report for thesixteen years 1946-1962. N Engl J Med 1962;267: 916-23. DOI: http://dx.doi.org/10.1056/NEJM1962102526 71707

8. Benor DE. A new paradigm is needed for medical education in the mid-twenty-first century andbeyond: are we ready? Rambam Maimonides MedJ. 2014;5(3):e0018. DOI: http://dx.doi.org/ 10.5041/RMMJ.10152.eCollection 2014.

9. Bean RB, Bean WB. Sir William Osler: Aphorismsfrom his Bedside eachings and Writings. New York: H. Schuman; 1950.

10. Rukeyser, Muriel, Speed of darkness, Stanza IX. New York, Random House (1968). 